\title{
La presencia de la publicidad en la composición visual de los diarios online
}

\section{Advertising presence on the visual configuration of the digital press}

\author{
Belinda de Frutos Torres \\ Profesora Contratada Doctora \\ (Universidad de Valladolid) \\ Noemi C. Martín García \\ Alumna de doctorado \\ (Universidad de Valladolid)
}

Fecha de recepción: 3 de abril de 2016

Fecha de revisión: 29 de mayo de 2016

Para citar este artículo: de Frutos Torres, B. y Martín García N. C. (2016):

La presencia de la publicidad en la composición visual de los diarios online, Icono 14, volumen 14 (2), pp. 204-230. doi: 10.7195/ri14.v14i2.957 


\section{Resumen}

El poder de la imagen es uno de los principales motores de cambio que se ha dado en la prensa con la aparición de internet y la evolución de las TIC. El presente estudio analiza cómo es la estructura que está utilizando la prensa digital y qué papel representa la publicidad respecto a los elementos textuales e icónicos que forman el periódico. El trabajo cuantifica y compara el papel de la imagen y la publicidad en los diarios online considerados nativos, es decir aquellas que han nacido en la red, con los procedentes de un soporte impreso. El análisis revela que los diarios on-line nativos presentan mayor volumen publicitario en detrimento del contenido informativo. Al mismo tiempo se constata una mayor presencia de la información gráfica en los primeros. En conjunto puede afirmarse que el componte visual domina las portadas de ambos tipos de diarios digitales, si bien en los diarios nativos digitales este efecto está más agudizado.

Palabras clave: Periodismo digital - Publicidad digital - Estructura de la prensa online - Volumen publicitario - Composición visual

\section{Abstract}

Visual strength is responsible for one of the mayor changes undergone by the digital press with Internet explosion and the increase of the Informational and Communicational Technologies. The present study analyzes the structure the digital press has taken and the role of the digital advertisement in the composition of their textual and iconic elements. The paper quantifies the picture representations volume and compares their presence on the digital natives papers with those coming from the traditional paper support. The results reveal that there is a mayor contribution of adverts on the native on-line press compare to the on-line paper arriving from the traditional media decreasing the information volume. At the same time the visual volume is boosted on the former compare to the digital media with a paper support. Altogether it can be said that visual component prompted the digital papers first page, being this effect enhanced on the native digital papers.

Key Words: On-line press - On-line advertising - Digital press structure - Adverts volume - Visual composition 


\section{Introducción}

En la actualidad la prensa se enfrenta a uno de los principales desafíos, la pérdida de financiación procedente de la inversión publicitaria en su soporte tradicional, al mismo tiempo que se consolida el acceso de los contenidos a través de Internet. Según Infoadex (2015) los ingresos publicitarios de los diarios tradicionales descendieron desde 2007 más de un $65 \%$. Por su parte la prensa digital se ve cada vez más respaldada por los anunciantes, al mismo tiempo que se incrementa el porcentaje de lectores que acceden a sus contenidos únicamente en soporte digital (Peña, Lazkano y García 2016). A pesar de ello sus ingresos no siempre son suficientes para sostener un modelo de financiación basado solamente en la comercialización de espacios publicitarios. Autores como Goyanes (2012), Varela (2003), Armentia (2011) o Casero Ripollés (2012) han analizando la viabilidad financiera de la prensa digital, situando el pago por determinados contenidos como un modelo posible para asegurar la supervivencia del fenómeno junto con los ingresos proporcionados por la publicidad.

El interés del presente trabajo se centra en el papel de la publicidad en la composición visual de los diarios digitales. La revisión sobre el diseño de la prensa digital en España sirve de base para el estudio de esta cuestión.

La transición de los diarios a un modelo digital se ha producido de forma paulatina. El termino ciberperiodismo nació a finales del siglo XX para referirse al periodismo que se desarrolla por y para el medio Internet, fue definido por Díaz y Meso (1999:18) como "una forma de comunicación que, tomando como modelos el periódico tradicional sobre papel, intenta constituirse en un nuevo medio de comunicación, con características e idiosincrasia propias". Varios autores han destinado sus líneas de investigación a este campo poniendo de manifiesto las continuas evoluciones y cambios que se han ido desarrollando con el avance de las nuevas tecnologías (Armañazas, Díaz y Meso 1996; Parra y Álvarez 2004; Flores y Miguel 2001, Canga 2005; Peña, Pérez y Genaut 2010, entre otros).

La prensa online se ha desarrollado en varias fases hasta definirse en lo que conocemos hoy, etapas que le han servido para depurarse y constituirse como 
un elemento diferente de la prensa tradicional y de otros tipos de publicaciones impresas y online. Los antecedentes más lejanos los encontramos con llegada de los ordenadores y de los programas de edición a las redacciones de los diarios. El profesor Meso (2006) habla de tres hitos: en 1970 con la llegada de la fotocomposición y offset; un segundo momento en los años 80 con la llegada del ordenador a la redacción, y una tercera en la década de los 90 con la entrada del color, la infografía y los nuevos programas de edición. La integración de estas tecnologías en el trabajo del periodista facilitó su labor y la producción de los diarios se hizo más rápida en la medida en que los tiempos del proceso de elaboración de los diarios disminuyeron significativamente. Ya entonces se evidencia cómo la tecnología está detrás de los cambios y retos en el modo de trabajar en la actividad de la prensa escrita.

La aparición de la Word Wide Web en 1990 proporcionó el avance tecnológico que hizo posible el nacimiento de la prensa digital. Al igual que ocurriera en el periodo anterior, la incorporación de los contenidos se realizó paulatinamente, y entre 1995 y 1999 los editores y directores de los principales diarios impresos españoles deciden adentrarse en el mundo de la red "volcando" el contenido de sus diarios en internet (Armentia 2005). En realidad la única innovación se centra en la accesibilidad del contenido desde Internet, puesto que se trataba de una simple copia en $\mathrm{pdf}$ o html de la edición impresa o un resumen del mismo sin acondicionarlos a los beneficios de la red de redes (Armentia 2005; Salaverría y Sancho 2007).

Un punto de inflexión viene marcado por un acontecimiento clave, los atentados del 11 de septiembre de 2001 que sufrió la ciudad de Nueva York con la caída de las Torres Gemelas (Palomo 2005). En ese momento los periódicos se dan cuenta de una de las ventajas de la red, la rapidez con la que pueden trasladar la información a los lectores, junto con la posibilidad de utilizar imágenes y sonidos para aumentar el contenido noticioso, etc... Como expone Salaverria “... la tragedia del 11-S contribuyó a que algunos cibermedios experimentaran por primera vez con productos multimediáticos que integraban de manera simultánea textos, imágenes y sonidos" (Salaverria 2004: 42). 


\subsection{Diseño de la prensa digital}

A partir de 2001 se habla de la prensa online como un nuevo fenómeno que une las características de la prensa tradicional con las ventajas que aporta internet. Entre ellas destacan la multimediedad, es decir, la capacidad de contener las ventajas de otros medios (Guallar, Rovira y Ruiz 2010; Bachmann y Marlow 2012 o Pérez Martínez 2009); la hipertextualidad, que posibilita enlazar unos textos 0 elementos con otros (Pérez Marco 2004; González 2006; Fontevila i Gascón 20110 Fondevila i Gascón y Segura 2012); la interactividad que permite poder mantener una comunicación bidireccional con el lector (Goldenberg 2005; Orejuela 20150 Navarro 2009) y la actualización constante de sus noticias (Albornoz 2011).

Al tiempo que se incorporan las ventajas de las posibilidades técnicas, el diseño de los diarios digitales vive importantes cambios, una cuestión que no ha sido tan tratada en la investigación académica. Salaverría y Sancho (2007) analizaron la evolución de la prensa digital desde el punto de vista del diseño e identificaron cuatro periodos bien diferenciados entre 1995 y 2007 marcados cada uno por una idea principal: "experimentación (1995-1998), homogeneización (1998-2001), inmovilismo (2001-2005) y renovación a partir de 2005" (pp. 5). Además de los continuos cambios en el diseño de los diarios Salaverría y Sancho (2007) destacan la diferenciación gráfica cada vez más acusada entre la versión impresa de los diarios y su versión digital, al mismo tiempo que se produce mayor similitud entre los diarios digitales entre sí, cuestión que ha sido también señalada por Canga (2005). El análisis de la estructura y diseño de los diarios digitales realizado por Armentia (2005) evidenció que en su mayoría seguían una estructura tridente que describe como "un bloque central informativo, flanqueado lateralmente con dos columnas, una (la izquierda) para el menú de navegación y otra (la derecha) para los servicios, publicidad y promociones" (Armentia 2005: 17). La estructura convive con otra denominada tetradente, una variación de la anterior, que en el bloque central incluye dos columnas en lugar de una (Armentia 2005). De este modo la columna de la derecha queda definida para la publicidad y otras funciones no informativas, según este mismo autor. Guallar (2007), por su parte, corrobora esta estructura tridente e investiga el momento en el que un grupo importante de diarios abandonan la barra vertical en la navegación, hecho también constatado posteriormente 
MONOGRÁFICO

(Salaverria y Sancho 2007; Caminos, Marín y Armentia 2008; Cabrera 2009), dando lugar a un diseño marcado por la horizontalidad de los contenidos.

Estudios más recientes se han ocupado del diseño poniendo el foco de análisis en la información y su modo de presentación en los diarios en términos de usabilidad (Peña, Pérez y Genaut 2010; Acosta-Valdés, Ramírez-Céspedes y Marcelo- Santana 2010), o la presencia de la fotografía en la portada de los diarios digitales en España (López del Ramo, 2010). A pesar de que la publicidad está muy presente en los diarios digitales desde sus comienzos, apenas hay referencias a su presencia cuando se estudia el diseño y la estructura de los diarios. A este respecto destaca el estudio realizado por Cabrera (2009) que describe, entre otras cuestiones, las características visuales de los principales diarios españoles en su versión digital. Cabrera (2009) constata que en conjunto hay mayor número de elementos textuales que icónicos, contabilizando los anuncios publicitarios, si bien en la mayor parte de los diarios analizados domina la imagen sobre el texto. El trabajo ratifica la mayor presencia de la imagen en el entorno interactivo, una tendencia adoptada en general por los diarios digitales según apuntaba Canga (2005), si bien el estudio registra el número de elementos pero no da cuenta del espacio que ocupan en la composición de la página.

\subsection{La publicidad en la prensa digital}

Por su parte, la publicidad en los medios interactivos ha pasado, al igual que los diarios digitales, por distintas etapas. Los primeros momentos vinieron marcados por la indefinición y por la exploración de nuevos formatos ante las posibilidades técnicas que dieron como resultado la necesidad de estandarización (IAB 2005). En un estudio realizado por Sánchez y Frutos (2008) se puso de manifiesto la variedad de formatos y tamaños que adoptaba la publicidad en las páginas web que sobrepasaba con creces los estándares marcados por la IAB en ese momento. Junto a la explosión de creatividad del primer periodo, empieza a surgir el rechazo a la publicidad, siendo la interferencia el aspecto más molesto para el usuario (Frutos y Gutiérrez 2005). Muela (2008) plantea la necesidad de integrar de forma natural los mensajes publicitarios con el contenido para que el receptor no lo asocie a una invasión de sus espacios. La constatación de que los formatos denominados 
intrusivos, es decir, que escapan del control del usuario generan mayor molestia entre los usuarios, particularmente si interfieren en su actividad, llevó a la desaparición paulatina de este tipo de recursos (Frutos y Sánchez 2011). Como consecuencia la publicidad ha derivado en formatos menos intrusivos (Carillo y Castillo 2005) al mismo tiempo que surgen otros nuevos más centrados en la integración con el contenido como el advertainment, branded content y fashion films como señalan Del Pino y Castelló Martínez (2015).

Un trabajo reciente publicado por Cea (2014) analiza el volumen de publicidad en seis categorías de páginas webs: periódico, revista, broadcaster, agencia, medio nativo y agregador, y concluye: " (que los periódicos) responden a un modelo publicitario que se caracteriza por una mayor presencia de anuncios gráficos, con una mayor diversidad de formatos y con un mejor uso de la interactividad en sus piezas" (Cea 2014; 65). No obstante, el citado trabajo no se ocupa del equilibrio entre contenidos y publicidad, una cuestión necesaria para valorar la integración de la publicidad con los contenidos informativos.

\section{Planteamiento y objetivos}

El diseño de la prensa digital ha pasado por varias etapas que han configurado su posición como se conoce hoy en día. En esta evolución se aprecia la convergencia hacia una composición similar, la denominada estructura tridente que define la ubicación de los contenidos del diario y el espacio dedicado a la publicidad con una distribución horizontal de los contenidos. Por otra parte, los formatos publicitarios en el medio interactivo, ante la molestia generada por determinados recursos creativos, ha buscado una mayor integración en el soporte. Al mismo tiempo, se produce una evolución del medio interactivo hacia una mayor presencia de la imagen frente al texto, compartiendo códigos utilizados con frecuencia en la publicidad. Por ello, resulta pertinente el análisis de la composición de los diarios digitales y su ponderación entre los contenidos informativos y los publicitarios, temática que no ha sido abordada previamente en los estudios de este área. 


\section{MONOGRÁFICO}

\section{Objetivo del estudio}

El estudio trata de evidenciar hasta qué punto la dependencia financiera de los diarios nativos digitales condiciona su espacio dedicado a la publicidad, al tiempo que también subordina el volumen de sus informaciones y el predominio de la imagen frente al texto. Para ello se procede a cuantificar el volumen publicitario de los diarios digitales.

La hipótesis de partida es que el tipo de diario condicionará su ocupación publicitaria, así los diarios nativos digitales, es decir, que no cuentan con el apoyo de una cabecera impresa tendrán mayor ocupación publicitaria. Asimismo se plantea que la mayor presencia publicitaria repercute en la composición visual de los diarios, por lo tanto, se espera que los diarios nativos digitales muestren mayor información gráfica que los diarios procedentes de una cabecera impresa.

Para poner a prueba la hipótesis se compara:

- El volumen publicitario e informativo de los diarios online nativos versus los que tienen apoyo de cabecera impresa.

- El volumen de información textual y gráfica de los diarios online nativos versus los que tienen apoyo de cabecera impresa.

- El contenido visual y semántico de los diarios online nativos versus los que tienen apoyo de cabecera impresa.

Para implementar el trabajo de campo se llevará a cabo un estudio previo para comprobar la estructura de los diarios digitales y establecer una rejilla que permita la cuantificación del volumen publicitario de una forma estandarizada y que pueda ser aplicada a todos los soportes bajo estudio.

\section{Objetivos del estudio previo}

El objetivo de este estudio previo se centra en conocerla estructura de los diarios digitales españoles en cuanto a la composición de sus contenidos. Los objetivos específicos del estudio preliminar se centran en: 
- Comprobar si la estructura visual de los diarios online sigue el modelo denominado tridente 2015 en todos los soportes independientemente de la tipología.

- Establecer una rejilla de ocupación que permita la comparación entre soportes.

Para ello se ha tomado como referencia la estructura tridente planteada por Armentia (2005) incorporando la modificación posterior que eliminaba la barra de navegación vertical (Guallar 2007; Caminos, Marín y Armentia 2008; Cabrera 2009). A esta nueva estructura se le ha denominado Tridente 2015 que mantiene los principios básicos de la primera definición de Armentia (2005) pero con las modificaciones aportadas por las investigaciones posteriores, como se muestra en la figura 1.
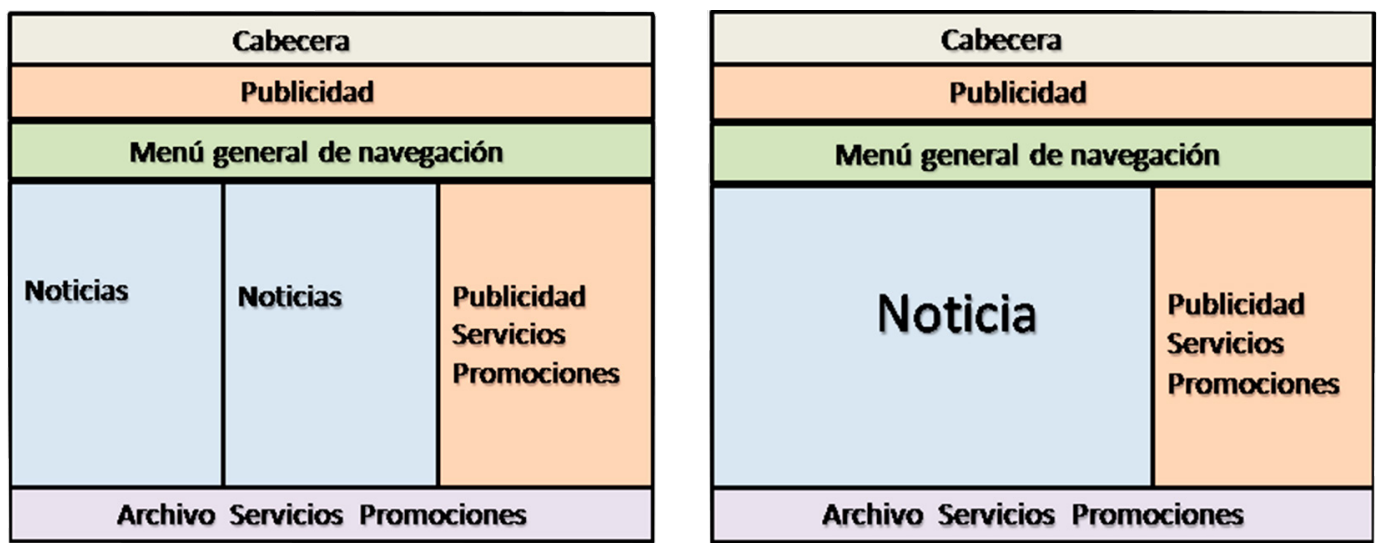

Figura 1: Estructura Tridente 2015 en portada y noticias

\section{Metodología del estudio previo}

El método elegido para llevar a cabo el primer estudio ha sido la observación de campo. Mediante una observación no intrusiva se pretende comprobar si la estructura de los periódicos online se corresponde con la tridente 2015 según se ha descrito anteriormente. 


\section{MONOGRÁFICO}

El universo bajo estudio está formado por los periódicos online publicados en España. Para su identificación se ha utilizado la base de soportes digitales que presenta la 0JD Interactiva (2014). No obstante, al detectar que algunos soportes de referencia en la prensa digital no estaban incluidos en los datos de la 0JD interactiva ${ }^{1}$, esta fuente se ha complementado con los soportes aportados por el universo de Infoadex (2015), referente de la inversión publicitaria, que aunque reúne a un universo más reducido incluye los soportes que tienen mayor impacto desde el punto de vista publicitario.

Para la elección de la muestra se ha llevado a cabo un análisis previo de los diarios digitales según tres criterios de clasificación basados en las tipologías de prensa que presenta el EGM: ámbito geográfico, naturaleza de los contenidos y apoyo de soporte impreso.

El primer criterio se centra en el ámbito de interés de las noticias que contienen, que lleva a diferenciar entre los diarios de carácter local y nacional.

- Local: Si contienen básicamente información procedente de una localidad o ámbito geográfico particular, aunque den breves pinceladas de la actualidad nacional. En esta categoría se sitúan diarios provinciales como sorianoticias. com, diariodealmeria.es o de carácter autonómico como madridiario.es, andaluciainformacion.com, diaricatala.cat, etc.

- Nacional: Si el mayor porcentaje de su información son noticias de carácter nacional, por ejemplo en este caso estarían libertadigital.com o estrelladigital.es.

El segundo criterio viene marcado por la naturaleza de la información que contienen siendo agrupada en los diarios generalistas y específicos:

- Generalistas: Se incluyen los diarios que dan prioridad a las noticias de carácter general política, cultura, deporte, ocio, etc.; diarios como libertadigital.com o elpais.es estarían en esta categoría. 
La presencia de la publicidad en la composición visual de los diarios online $\mid 214$ MONOGRÁFICO

- Específicos: Recogen soportes que ofrecen información de temas específicos como deportes, salud, etc..; un ejemplo de ello lo encontramos en diarios deportivos como marca.com o as.es.

El último criterio utilizado para clasificar la prensa on-line se basa en el respaldo impreso del periódico online, de esta manera obtenemos:

- Cabeceras con apoyo de soporte impreso, es decir, soportes que lanzaron una versión online del soporte cuando ya tenían una versión impresa. Diarios como elpais.com, marca.com, elmundo.es y otros muchos, pertenecen a este grupo, ya que la mayor parte de los diarios impresos tienen una versión online disponible en internet.

- Cabeceras sin apoyo de soporte impreso diarios nativos digitales, que agrupan a soportes que han nacido en el entorno de la web y que no están respaldados por una edición impresa. En esta categoría se sitúan diarios como libertaddigital.es y estrelladigital.com, entre otros.

Los criterios utilizados no son mutuamente excluyentes, de modo que para la elección de la muestra se realiza una selección de 5 soportes pertenecientes a cada categoría, en total se han analizado 30 soportes.

Una vez elegida la muestra se procedió al análisis de su estructura, para ello se realizó la captura de pantallas el día 4 de diciembre de 2015 entre las 8:00 y 23:59 horas. Así se recogió en cada soporte un pantallazo de la portada y otro del enlace a una de sus noticias elegidas al azar.

\section{Resultados del estudio previo}

En el análisis se comprobó si el diario poseía o no la estructura Tridente 2015. Los resultados, que se muestran en la tabla 1, vienen a corroborar que la mayor parte de los soportes tienen la estructura Tridente 2015 en la portada y en las noticias. Por una parte, los soportes presentan una estructura coherente entre la portada y las noticias, de modo que si la primera página tiene la estructura

DOI: ri14.v14i2.957 | ISSN: 1697-8293 | Año 2016 Volumen 14 Nº 2 | ICONO14 


\section{MONOGRÁFICO}

tridente, esta se mantiene en el interior de las noticias en la mayor parte de los casos. El $87 \%$ de los soportes analizados mantienen la estructura tridente independientemente de la tipología. La única desviación se produce en los soportes especializados y los que no cuentan con el apoyo de una cabecera impresa. A pesar de ello el porcentaje de cumplimento de la estructura supera el $50 \%$ con lo que se puede afirmar que la estructura Tridente 2015 es la estructura prioritaria de los diarios online.

\begin{tabular}{|c|c|c|}
\hline & $\begin{array}{c}\text { Estructura Tridente } \\
2015-\text { Portada- }\end{array}$ & $\begin{array}{c}\text { Estructura Tridente } \\
2015-\text { Noticias- }\end{array}$ \\
\hline Unidad de análisis & $\mathbf{N}^{0}$ de Diarios & 5 \\
\hline Generalista & 5 & 3 \\
\hline Especializado & 3 & 3 \\
\hline Local & 5 & 5 \\
\hline Nacional & 5 & 5 \\
\hline Con cabecera impresa & 5 & 3 \\
\hline Sin cabecera impresa & 3 & $\mathbf{8 0 \%}$ \\
\hline TOTAL (\%) & $\mathbf{8 7 \%}$ & \\
\hline
\end{tabular}

Tabla 1: Presencia de la estructura tridente 2015 en los diarios digitales según su tipología

Este primer estudio ha permitido corroborar que la estructura tridente se mantiene presente en la mayor parte de los diarios digitales ocho años después de su última modificación, indicativo de que los diarios digitales han alcanzado estabilidad en cuanto a la disposición de los contenidos y la publicidad. En la observación se ha constatado que aunque el volumen de publicidad varie de unos diarios a otros suele aparecer siempre en la tercera columna de la estructura tridente, tan sólo ocasionalmente aparece en las dos primeras columnas destinadas a la información, siendo esta ocupación escasa. Igualmente se advierte que 
hechos noticiosos extraordinarios pueden modificar la estructura tridente, como fue el caso de los atentados en París el 13 de noviembre de 2015, donde desaparecen las columnas para dar prioridad en todo el espacio a una única información. Finalmente, a partir de los resultados se puede definir una rejilla para cuantificar el volumen de ocupación de los contenidos informativos y de la publicidad de los diarios digitales que permitirá abordar el siguiente estudio.

\section{Metodología del segundo estudio}

La metodología elegida para el segundo estudio es el análisis de contenido. Este método goza de una dilatada experiencia en las investigaciones en torno a los medios de comunicación a la hora de abordar de forma sistemática el contenido de los medios en su contexto que pueden ser cuantificados (Kerlinger 1986; Bardin 1991; Wimmer y Dominick 1996).

Para llevar a cabo el análisis se han elegido dos diarios online, un soporte que cuenta con una cabecera impresa y otro nativo digital, es decir, sólo cuenta con su versión web. Partiendo de las tipologías de la prensa digital utilizadas en el anterior estudio, se ha optado por elegir soportes generalistas. El volumen de publicidad de los soportes específicos depende en cierta medida de la temática que tengan, y en consecuencia, puede resultar más dificil su comparación. Asimismo, los soportes seleccionados pertenecen al ámbito local, si bien ambos reciben visitas desde cualquier ubicación geográfica. Se ha optado por esta modalidad al considerar que hay menos competencia publicitaria que en el ámbito nacional, donde entran en juego otros medios como la televisión o la radio, que otorgan una cobertura mayor al mensaje.

El soporte seleccionado para representar el diario digital que cuenta con una cabecera impresa ha sido elpais.com. El diario El País es uno de los diarios que goza de mayor prestigio entre los lectores y los anunciantes, tanto en su versión impresa como digital. Lidera el ranking de diarios digitales en visitas en internet (EGM 2015) con un promedio de visitas mensuales ${ }^{2}$ de 6.203 .000 (Comscore 2015). Para el estudio se eligió la edición Madrid del diario. 
El diario nativo digital elegido ha sido madridiario.es ${ }^{3}$. Este soporte, destinado a información local de la Comunidad de Madrid, nació en el año 2000, cuenta entre sus filas con más de una treintena de profesionales, tiene un promedio de 74.000 visitas mensuales (Comscore 2015) y 7.758 usuarios únicos al día (0JD interactiva 2015). Entre sus anunciantes se encuentran empresas de carácter nacional que ocupan los primeros puestos en los rankings de inversión publicitaria gestionada como El Corte Ingles, La Caixa, BBVA, Renfe e Iberdrola entre otros.

Para garantizar la comparabilidad de los soportes, el estudio se lleva a cabo en el mismo número de unidades de análisis, al margen de la extensión de cada diario. Por una lado se analiza la portada ${ }^{4}$, es decir, la primera imagen que tiene el lector del soporte, y además se incorporarán dos noticias elegidas al azar dentro de las páginas del diario. En el estudio no se analizan todas las noticias debido a que el espacio dedicado a la publicidad es el mismo en todas ellas, incluso el contenido publicitario suele ser el mismo, independientemente del tipo o la extensión de la noticia, según se pudo constatar en los análisis exploratorios previos. Para acceder a este contenido se capturan estos elementos a la misma hora durante una semana tipo. En el soporte madridiario.es se realizó una captura diaria a las 10:00 horas desde el 23 al 29 de noviembre de 2015. En el diario elpais.com la recogida de datos se realizó a las 10:00 de la mañana durante la semana del 8 al 14 de febrero de 2016. Desde el punto de vista de la inversión publicitaria los meses de febrero y noviembre son similares por lo que ambos periodos pueden ser equiparables para el análisis.

A continuación se define la unidad de análisis de las páginas capturadas. Teniendo en cuenta que la totalidad del contenido de la página web de un diario no es visible en un único pantallazo, se decide dividir cada captura en cinco pantallazos ${ }^{5}$, de esta manera se garantiza que el análisis de la página sea íntegro. La unidad de análisis será el pantallazo, de modo que contamos con una muestra de 70 unidades de análisis para las portadas y 140 unidades para las noticias. 
Una vez concretada las unidades de análisis, se define una rejilla para cuantificar el espacio dedicado a cada una de las categorías registradas. Tomando la estructura tridente 2015 confirmada en el primer estudio cada pantallazo se divide en tres columnas iguales y en cuatro secciones horizontales, de manera que se crea una tabla de 12 celdas o unidades de registro. Estas unidades de registro serían equivalentes a los módulos utilizados en la composición de los diarios impresos.

\begin{tabular}{|c|c|c|}
\hline 1 & 2 & 3 \\
\hline 4 & 5 & 6 \\
\hline 7 & 8 & 9 \\
\hline 10 & 11 & 12 \\
\hline
\end{tabular}

Figura 2: Rejilla que define las unidades de registro

Finalmente se definen las categorías del análisis de contenido. Teniendo en cuenta el propósito del estudio en cada unidad de análisis se constata la presencia de información de texto, información gráfica o publicidad. En cada pantallazo del proceso de codificación se registra la presencia de información de texto (noticias), información gráfica (imagen) o publicidad (anuncio publicitario), y se cuantifica el número de celdas o unidades de registro que ocupa cada uno.

En la categoría de información de texto se considera noticia cada vínculo que hay dentro de la portada que enlaza a otra página con contenido informativo del propio diario. No se considera noticia los elementos que envían al lector a otra página web corporativa de otra empresa, en cuyo caso se contabiliza como un anuncio y se cuantifica su volumen en la portada; en el caso en el que anuncio enlaza a una página web del anunciante, también se cuantifica como contenido publicitario. Durante el proceso de obtención de los datos se han tenido en cuenta otras consideraciones ${ }^{6}$. 
219 | Belinda de Frutos Torres y Noemi C. Martín García

MONOGRÁFICO

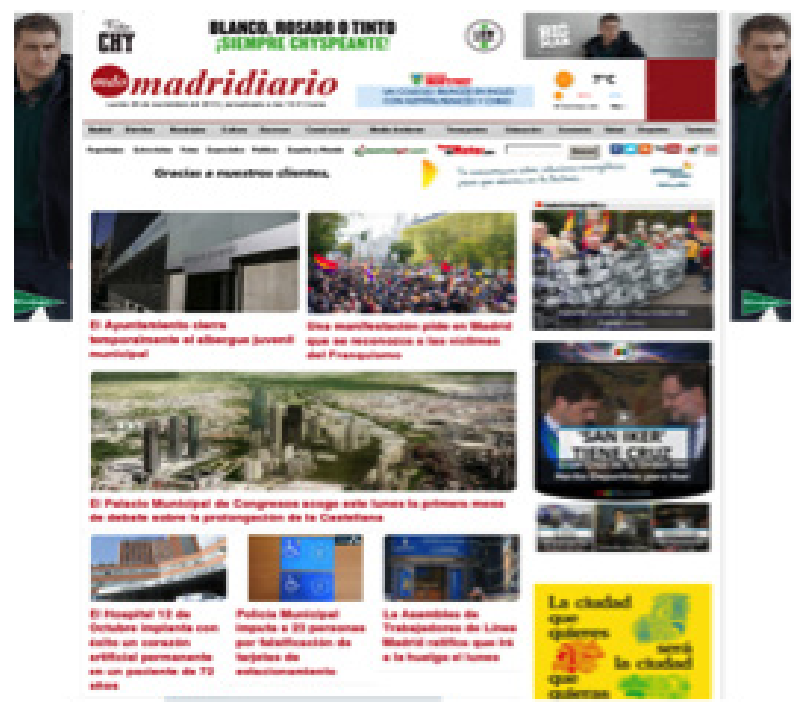

Figura 3: Pantallazo 1 Portada madridiario.es día 23 de noviembre de 2015
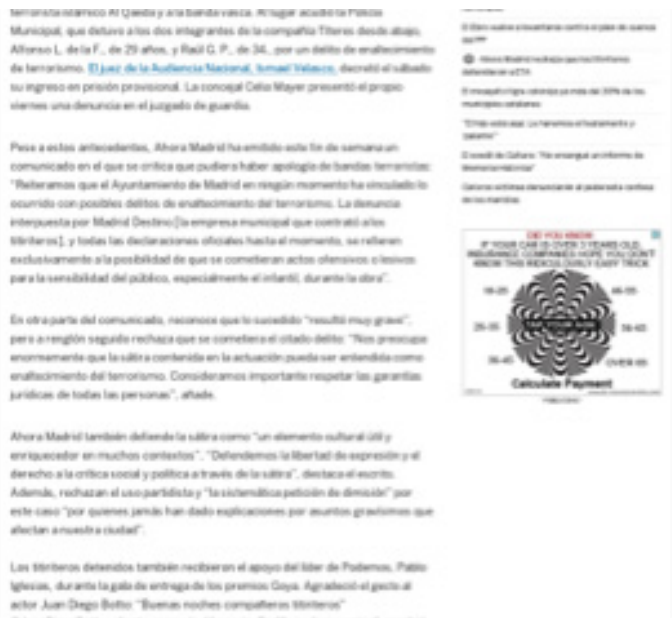

Figura 4: Pantallazo 3 Noticia elpais.com/madrid día 8 de febrero 2016

Una vez calculada la ocupación de cada categoría se obtiene el porcentaje de ocupación respecto al total del pantallazo. Tanto las portadas como los enlaces a las páginas a veces incluyen módulos en blanco, es decir no siempre cubren todo el espacio disponible. Para que el porcentaje de ocupación no se vea distorsionado por la extensión de los contenidos este se ha calculado sobre los módulos ocupados. 


\section{Resultados del segundo estudio}

Para el análisis de resultados se ha calculado el promedio de la ocupación en cada categoría. Antes de proceder a las comparaciones cabe señalar la diferencia de ocupación entre ambos soportes. El espacio en blanco en elpais.com no sobrepasa el 10\% del total analizado, mientras que en el madridiario.es el $23 \%$ de los módulos no poseen ninguno elemento. Es decir, la edición de Madrid del diario elpais.com tiene más volumen informativo.

La distribución del espacio en los diarios analizados se muestra en el gráfico 1. Tanto en las portadas como en las páginas interiores analizadas hay diferencias entre ambos soportes. El diario elpais.com dedica mayor volumen a los contenidos informativos de texto, tanto en la portada (46\%) como en el interior de las noticias (57\%). La información gráfica de este soporte ocupa el 35\% en la portada y el $23 \%$ del espacio en las páginas de noticias enlazadas. Finalmente, el espacio dedicado a publicidad ocupa prácticamente el mismo espacio en la portada (19\%), que en el espacio dedicado a las noticias enlazadas (20\%).

\section{Volumen de ocupación de los soportes}

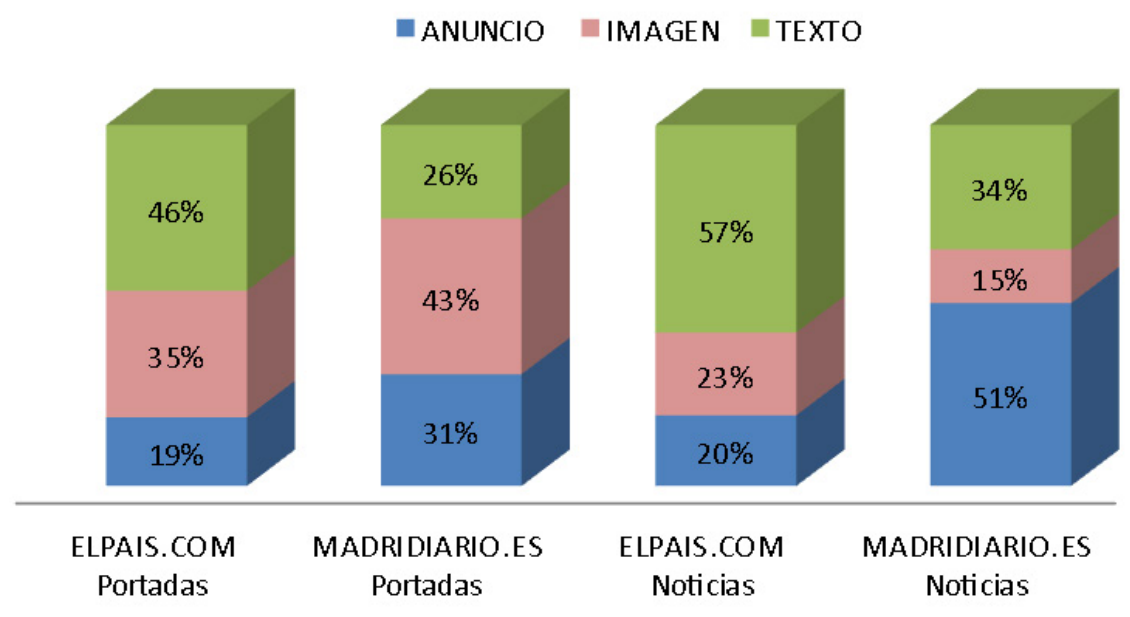

Figura 5: Volumen de ocupación de los soportes bajo estudio 


\section{MONOGRÁFICO}

El segundo soporte madridiario.es en su portada dedica mayor espacio a la información gráfica (43\%) aunque en sus páginas interiores esta se reduce al $15 \%$ del espacio. La información textual de la portada ocupa un $26 \%$ y en los enlaces a las páginas interiores el contenido de texto alcanza el 34\%; el espacio dedicado a la publicidad en la portada llega al 31\% y en sus páginas interiores se amplía hasta el 51\% del espacio ocupado. En conjunto se aprecia que el diario nativo digital da más importancia a la información gráfica en su portada y la publicidad ocupa mayor espacio tanto en la portada como en los enlaces a las páginas de noticias.

A continuación se ponen a prueba las hipótesis planteadas en el trabajo, para ello se va a utilizar el estadístico chi-cuadrado que permite contrastar si las diferencias entre las proporciones alcanzan la significación estadística. En primer lugar se compara el volumen dedicado a la información (textual o gráfica) y la publicidad entre ambos tipos de diarios. En la tabla 2 se muestra el resultado de las comparaciones. El diario con soporte impreso dedica un $81 \%$ de espacio a la información en su portada, frente al $69 \%$ del diario nativo digital. La diferencia entre ambos soportes es estadísticamente significativa (chi-cuadrado $=3,840 ; 1$ g.l.; $\mathrm{p}=0,036)$. Esta diferencia es más evidente si la comparación se realiza sobre los enlaces de las noticias, así la información en el diario elpais.com alcanza el 80\% de los contenidos frente al $49 \%$ del diario madridiario.es. El estadístico de contraste muestra que esta diferencia es estadísticamente significativa (chi-cuadrado = 20,$985 ; 1$ g.l.; $\mathrm{p}=0,000$ ). Por lo tanto, se confirma que el diario nativo digital dedica mayor espacio a los contenidos publicitarios que el diario con respaldo impreso tanto en la portada como en los enlaces a las noticias.

\begin{tabular}{|c|c|c|}
\hline & $\begin{array}{c}\text { Diario digital con } \\
\text { soporte impreso } \\
\text { Elpais.com ed. Madrid }\end{array}$ & Diario nativo digital \\
\hline Portada & $\%$ col. & Diariomadrid.es \\
\hline Información & 81 & 69 \\
\hline Publicidad & 19 & 31 \\
\hline
\end{tabular}




\begin{tabular}{|c|c|c|}
\hline & $\begin{array}{c}\text { Diario digital con } \\
\text { soporte impreso } \\
\text { Elpais.com ed. Madrid }\end{array}$ & Diario nativo digital \\
\hline Chi - cuadrado & 3,$840 ; 1$ g.l. $(\mathrm{p}=0,036)$ & \\
\hline Enlaces a noticas & 80 & 49 \\
\hline Información & 20 & 51 \\
\hline Publicidad & 20,$985 ; 1$ g.l. $(\mathrm{p}=0,000)$ & \\
\hline Chi - cuadrado & & \\
\hline
\end{tabular}

Tabla 2: Comparación del volumen de ocupación de contenidos informativos y publicitarios

La siguiente cuestión abordada se centra en estudiar si ambos tipos de diarios difieren en la presencia de la información gráfica frente al texto. En este sentido se compara la información visual y de texto en ambos soportes. Según recoge la tabla 3 en la portada del soporte nativo digital hay mayor presencia de contenidos visuales (43\%), al mismo tiempo que hay menor presencia de información textual (26\%). En cambio, en el soporte elpais.com, la información textual de la portada supone el $46 \%$ de los contenidos, frente a un 35\% de información gráfica. Estas diferencias alcanzan la significación estadística (chi-cuadrado $=5,451 ; 1$ g.l.; $\mathrm{p}=0,020$ ).

\begin{tabular}{|c|c|c|}
\hline & $\begin{array}{c}\text { Diario digital con } \\
\text { soporte impreso } \\
\text { Elpais.com ed. Madrid }\end{array}$ & $\begin{array}{c}\text { Diario nativo digital } \\
\text { Diariomadrid.es }\end{array}$ \\
\hline Portada & $\%$ col. & $\%$ col. \\
\hline Información textual & 46 & 26 \\
\hline Información gráfica & 35 & 43 \\
\hline Chi - cuadrado & 5,$451 ; 1$ g.l. $(\mathrm{p}=0,020)$ & \\
\hline
\end{tabular}




\section{MONOGRÁFICO}

\begin{tabular}{|c|c|c|}
\hline & $\begin{array}{c}\text { Diario digital con } \\
\text { soporte impreso } \\
\text { Elpais.com ed. Madrid }\end{array}$ & $\begin{array}{l}\text { Diario nativo digital } \\
\text { Diariomadrid.es }\end{array}$ \\
\hline \multicolumn{3}{|l|}{ Enlaces a noticas } \\
\hline Información textual & 57 & 34 \\
\hline Información gráfica & 23 & 15 \\
\hline Chi - cuadrado & 0,$051 ; 1$ g.l. $(p=0,822)$ & \\
\hline
\end{tabular}

Tabla 3: Comparación del volumen de ocupación de contenidos texto, imagen y publicidad

En los enlaces a las páginas de noticias se advierte que en ambos soportes el contenido visual es menor al contenido de texto. En elpais.com la información visual ocupa el $23 \%$, ello supone un porcentaje bastante inferior al dedicado a la portada, mientras que la información textual alcanza el 57\%. El madridiario.es presenta el mismo patrón, el contenido gráfico supone el 15\% de la ocupación, un porcentaje menor al dedicado en la portada y menor del que dedica el diario con soporte impreso; mientras que la información textual ocupa el 34\% del enlace a la página. La comparación entre ambos soportes no arroja diferencias estadísticamente significativas, chi-cuadrado=0,051 $(\mathrm{p}=0,822)$, por lo tanto, no hay diferencias entre la información de carácter gráfico entre ambos soportes en sus enlaces a las noticias.

Desde el punto de vista del diseño se podría decir que la imagen es el elemento dominante en la composición, teniendo en cuenta que la publicidad se compone en su mayor parte de imagen o elementos iconográficos. Esta superioridad es evidente en el diario nativo digital en su portada, según se muestra en la tabla 4, con un $84 \%$ de elementos visuales, y en los enlaces a las páginas de noticias con $66 \%$ de dominancia de las imágenes. En el diario con soporte impreso las diferencias entre los semántico y lo visual son menos fragrantes. A pesar de que en la portada también haya mayor dominancia de la imagen (54\%), en los enlaces a las páginas de noticias predomina el discurso (57\%). 


\begin{tabular}{|c|c|c|}
\hline & $\begin{array}{c}\text { Diario digital con } \\
\text { Soporte impreso } \\
\text { Elpais.com ed. Madrid }\end{array}$ & $\begin{array}{c}\text { Diario nativo digital } \\
\text { Diariomadrid.es }\end{array}$ \\
\hline Portada & $\%$ col. & 26 \\
\hline Contenido semántico & 46 & 84 \\
\hline Contenido visual & 54 & \\
\hline Enlace a noticias & 11,$625 ; 1$ g.l. $(\mathrm{p}=0,001)$ & 34 \\
\hline Contenido semántico & 57 & 66 \\
\hline Contenido visual & 43 & \\
\hline
\end{tabular}

Tabla 4: Comparación del volumen de ocupación de contenidos visuales y semánticos

De nuevo la comparación entre los tipos de soportes confirma que las diferencias entre ambos son estadísticamente significativas en la composición de sus portadas (chi-cuadrado $=11,625 ; \mathrm{p}=0,001)$ y en los enlaces de noticias (chi-cuadrado $=10,666 ; \mathrm{p}=0,001)$. Por lo tanto, queda demostrado que el diario nativo digital está más mediatizado por el componente visual.

\section{Conclusiones y Discusión}

En primer lugar el trabajo ha permitido poner en perspectiva el equilibrio entre la información y los contenidos publicitarios de la prensa digital. Hasta la fecha los estudios publicados sobre el diseño de los diarios en el entorno digital no había abordado esta cuestión. En el trabajo se pone de manifiesto que hay un predominio del componente visual, si tomamos en conjunto la información gráfica y los contenidos publicitarios. Este diseño centrado en la imagen aparece de una forma muy clara en la portada de los diarios analizados independientemente de su tipología. 
Tal y como se había planteado los diarios nativos digitales, es decir, que no cuentan con un soporte impreso de su edición tienen mayor ocupación publicitaria. Es evidente que los soportes nativos digitales, al tener mayor dependencia económica de la publicidad como fuente de ingresos, necesitan dedicar espacio a la publicidad, y esto podría explicar las diferencias encontradas entre ambos tipos de soportes respecto a su volumen publicitario. No obstante, se ha constatado que la información de texto en la redacción de las noticias es menor que en el otro tipo de diario, al margen de la extensión de la noticia. En este sentido se aprecia claramente cómo la mayor parte de su espacio se destina a la imagen, ya sea con anuncios, información gráfica u otros elementos iconográficos.

En los diarios digitales que cuentan con un respaldo impreso se mantiene la impronta de la función informativa, mostrando mayor hegemonía del mensaje sobre los contenidos publicitarios, que se aprecia de una forma clara en los enlaces a los contenidos de las noticias. Si bien, cuando se compara la información gráfica entre ambos tipos de diarios estos no difieren entre sí. Por lo tanto, parece que son los contenidos y la profundidad de su tratamiento los que marcan la diferencia entre ambos tipos de diarios.

La paulatina mayor dependencia de todos los diarios de los ingresos procedentes de la publicidad digital, teniendo en cuenta la pérdida de inversión publicitaria en los soportes impresos junto a la caída de lectores en papel, abre la posibilidad hacia la convergencia de los dos tipos de diarios analizados. El equilibrio entre la información y la publicidad es necesario, en la medida en que el soporte depende de los ingresos publicitarios para su supervivencia, al igual que el sistema publicitario tampoco puede pervivir sin información que interese a sus lectores. En consecuencia, habrá que seguir de cerca la evolución de los contenidos de los soportes digitales y corroborar esta tendencia hacia una mayor presencia de la imagen en la composición de la prensa digital, en consonancia con lo que está ocurriendo en otros soportes. Peña, Lazkano y García (2016) ratifican recientemente la lectura superficial de la información en los diarios digitales en el ámbito europeo asociada a su modo de presentación y al tiempo de permanencia en el soporte. Las implicaciones de esta tendencia ponen en cuestión el modelo informativo que tradicionalmente ha proporcionado la prensa. 
En otro orden de cosas, el estudio ha confirmado la estructura tridente de los diarios digitales con una organización horizontal de los contenidos que está prácticamente generalizada independientemente de su tipología. Además, se ha desarrollado una rejilla de análisis para cuantificar los contenidos de los diarios de una manera estandarizada que puede ser utilizado en posteriores trabajos de investigación en la prensa digital.

Otra cuestión que surge a raíz de los resultados lleva a plantear hasta qué punto los lectores de diarios digitales perciben de forma consciente las diferencias entre los dos tipos de diarios bajo estudio. Abordar esta cuestión implicaría centrar el análisis en la recepción y evaluar en qué medida los lectores son capaces de apreciar diferencias en el volumen informativo, la saturación publicitaria, entre otras, y cómo pueden verse afectadas cuestiones como la elección, la credibilidad o la legibilidad de los soportes.

Finalmente, cabe señalar algunas de las limitaciones de este trabajo. Su carácter exploratorio han llevado a implementar el estudio en dos soportes. Sería de interés poder extender la muestra a un mayor número de soportes y ratificar los resultados. Así mismo, el estudio se puede completar con el análisis de las tarifas publicitarias y la forma de comercialización en ambos tipos de soportes. Esta perspectiva permitiría dilucidar la rentabilidad de dos modelos de financiación diferentes y explorar formas alternativas en la explotación de los recursos.

\section{Notas}

[1] La inclusión en el sistema 0JD Interactiva se solicita voluntariamente por el soporte e implica asumir el sistema de medición que audita la entidad, por ello, algunos soportes deciden no integrarse en este protocolo de medición.

[2] Promedio de vistas a la home el país.com de abril de 2016 proporcionado por Comscore.

[3] Las audiencias de los diarios nativos digitales son muy inferiores en número a las obtenidas por los soportes que proceden de cabeceras impresas, por ello a la hora de elegir el soporte se ha tenido en cuenta el perfil de lector, el tipo de anunciante, además de los datos de audiencia.

[4] La portada o página principal en los diarios digitales reúne los contenidos del diario y tiene una función de índice del producto según señalan (Peña, Lazkano y García 2016).

[5] Se eligieron 5 pantallazos porque se corresponde con el número de veces que hay que descender la barra de scroll del ordenador para poder ver la totalidad de la página con un zoom medio del $50 \%$.

DOI: ri14.v14i2.957 | ISSN: 1697-8293 | Año 2016 Volumen 14 NN$^{\circ} 2$ | ICONO14 


\section{MONOGRÁFICO}

[6] Los pies de foto se consideran parte de la imagen ya que son complemento de esta y su función no se entiende si ella. El nombre de los soportes se considera una imagen aunque sea texto al contemplarse como logotipo. Si dentro de un mismo modulo encontramos dos unidades de análisis diferentes, se tendrá en cuenta aquella que ocupe un mayor espacio y sea la dominante. En la portada del diario digital madridiario.es al ser únicamente imágenes con titular inferior se contabilizaran los textos mediante la ocupación que tengan al agruparlos en módulos. No se tendrá en cuenta la publicidad que sobresale de los límites del propio diario, al estar fuera del formato de análisis. En las secciones de blog y similares del soporte madridiario.es que se estructuran bajo la forma de fotografía de la cara del autor más un titular, se contabiliza la mitad de la ocupación para cada unidad de análisis informativo: texto e imagen.

\section{Referencias}

Acosta- Valdés, M., Ramirez-Céspedes, Z., \& Marrero- Santana, L. (2010). Organización de la información en los sitios web periodisticos. El profesional de la información, 20 (1), 54-60.

Albornoz, L. A. (2011). Prensa digital: características de los principales diarios online en español. Revista latinoamericana de ciencias de la comunicación, 4, 122-132.

Armañazas, E., Diaz Noci, J., \& Meso Ayerdi, K. (1996). El periodismo electrónico. Barcelona: Ariel.

Armentina, J. I., Caminos, J. M., Elexgaray, J. \& Mercán, I. (2000). La información en la prensa digital: redacción, diseño y hábitos de lectura. Revista Zer, 8,183-212. Armentia Vizuete, J. I. (2005). Los diarios digitales siguen buscando su identidad tras una década de existencia. Estudios sobre el mensaje periodistico,11, 9-22. Armentia Vizuete, J. I. (2011). La difícil supervivencia de los diarios ante la agonia del papel. Ámbitos, 20, 11-27.

Bachmann, I., \& Marlow, S. (2010). La Interactividad y multimedialidad en los periodicos latinoamericanos, avances en una transición incompleta. Cuadernos de comunicación, 30, 41-52.

Bardin, L. (1991). Análisis de contenido.Madrid: Akal Universitaria.

Cabrera González, M. A. (2009). El diseño de la prensa digital española en el contexto de la convergencia tecnológica. La identidad visual del ciberperiodísmo. RLCS, Revista Latina de Comunicación Social, 64, 766 -786. doi: 10.4185/RLCS-64-2009-860-766-786

Caminos, J. M., Marín, F., \& Armentia Vizuete, J. I. (2008). Novedades en el diseño de la prensa digital española (2000-2008). Palabra Clave, 11 (2), 253-269.

Canga Larequi, J. C (2005). Periodismo en la Red. Diseño periodístico y ediciones digitales. Telos: Cuadernos de Comunicación, Tecnología y Sociedad, 63, 70-76. 
Carillo, M. V., \& Castillo, A. (2005). La Nueva Publicidad Digital (NPD) Servicios digitales y contenidos interactivos que generen "experiencias"en los consumidores. Razón y palabra, 45. Recuperado de : http://razonypalabra.org. $\mathrm{mx} /$ anteriores/n45/carrillocastillo.html

Casero-Ripollés, A. (2010). Prensa en Internet: Nuevos modelos de negocio en el escenario de la convergencia. El profesional de la Información, 19 (6), 595-601.

Cea Esteruelas, N. (2014). El modelo publicitario de los periodicos online. adComunica. Revista de Estrategias. Tendencias e Innovación en Comunicación, 7, 49-68. doi:http://dx.doi.org/10.6035/2174-0992.2014.7.4

Comscore. (2015). Estudio de audiencia de medios digitales.Comscore (programa informático). Recuperado de: http://www.comscore.com.

Del Pino, C., \& Castelló Martinez, A. (2015). La comunicación publicitaria se pone de moda: branded content y fashion flims. Revista mediterranea de comunicación, 6 (1), 105-128. doi: 10.14198/MEDC0M2015.6.1.07

Diaz Noci, J., \& Meso Ayerdi, K. (1999). Periodismo en internet, modelos de la prensa digital. Bilbao: Servicio editorial de la universidad de Navarra.

EGM. (2015). Estudio General de Medios.Tom Micro (Programa informático). Recuperado de: http://www.tommicro.com/

Flores Vivar, J., \& Miguel Arruti, A. (2001). Ciberperiodismo. Nuevos enfoques, conceptos y profesiones emergentes en el mundo infodigital. Madrid: Ediciones 2010.

Fondevila i Gaston, J. (2011). Aplicación semántica de la hipertextualidad en la prensa digital en España. En J. J. Verón Lassa, \& F. Sabés Turno, La investigación en periodismo digital: algunos trabajos desde el ámbito universitario, 169-180. Huesca: Asociación de la Prensa de Aragón.

Fondevila i Gascón, J., \& Segura Jiménez, M. (2012). El peso de la hipertextualidad en el periodismo digital: estudio comparativo. Cuadernos de comunicación, 30, 31-40.

Frutos Torres, B., \& Gutiérrez Zotes, P. (2005). Respuestas cogniticas de los usuarios a los contenidos publicitarios en "rich media". Mundo Internet.X Congreso Internet, Telecomunicaciones y Sociedad de la Información, 416-421. Madrid: AUI.

Frutos Torres, B., \& Sánchez Valle, M. (2007). La influencia del formato y la animación en el procesamiento de la publicidad en internet. Mundo Internet.XI Congreso Internet, Telecomunicaciones y Sociedad de la Información, 417-427. Madrid: AUI. Goldenberg, S. (2005). La interactividad, el desafio pendiente del periodismo online. Cuadernos de comunicación,18, 80-87. 


\section{MONOGRÁFICO}

González Rojas, I. (2006). La hipertextualidad desde el lector, no desde el autor. Revista de Comunicación, 25, 35-37.

Goyanes Martinez, M. (2012). Estrategias de pago por contenidos de la prensa digital: una aproximación teórica. Index Comunicación, 2 (1), 91-112.

Guallar, J. (2007). La renovación de los diarios digitales: rediseños y web 2.0. El profesional de la Información, 16 (3), 235-242. doi: 10.3145/epi.2007.may.08 Guallar, J., Rovira, C., \& Ruiz, S. (2010). Multimedialidad en la prensa digital. Elementos multimedia y sistemas de recuperación en los principales diarios españoles. $E l$ profesional de la Información, 19 (6), 620-629. doi: 10.3145/epi.2010.nov.08

IAB. (s.f.) Internactive Advertising Bureu. Recuperado de: http://www.iabspain. net/formatos-publicitarios/

Infoadex. (2015). Estudio de la Inversión publicitaria en medios. Recuperado de:http://www.infoadex.es/

Kerlinger, F. (1986). Foundations of Behavioral Research. New York: Holt, Rinehart and Winston.

López del Ramo, J. (2012). Análisis comparativo de las cabeceras de los diarios digitales españoles respecto a los impresos. Anales de documentación, 15 (2). doi:http://dx.doi.org/10.6018.analesdoc.15.2.150831

Meso Ayerdi, K. (2006). Introducción al ciberperiodismo. Breve acercamiento al estudio del ciberperiodismo. Bilbao: Servicio editorial de la Universidad del Pais Vasco.

Muela Molina, C. (2008). La publicidad en internet: situación actual y tendencias en la comunicación con el consumidor. Zer, Revista de Estudios de comunicación, 13 (24), 183-201.

Navarro Zamora, L. (2009). Tres lustros del periodismo digital: interactividad e hipertexto. Comunicar: Revista cientifica de comunicación y educación, 33, 3543. doi:10.3916/c33-2009-02-003

0JD. (2015). Oficina de Justificación de la Difusión. Usado el 1 de marzo de 2016 . Recuperado de: http://www.ojd.es/

OJD Interactiva. (2015). Oficina de Justificación de la Difusión de medios digitales. Recuperado de: http://www.ojdinteractiva.es/

Orejuela, M. (2015). Características del periodismo en linea venezolano. La interactividad y los cambios en las rutinas frente al resto de no sucumbir en el ciberperiodismo. Anuario electrónico de estudios de la comunicación social, 8 (1), 105-134. doi: dx.doi.org/10.12804/disertaciones.01.2015.05 
Palomo, M. B. (2005). Estructura editorial:diseño, navegación y usabilidad. En R. Salaverria, Cibermedios. El impacto de internet en los medios de comunicación es España, 186-222. Sevilla: Comunicación Social Ediciones y Publicaciones.

Parra Valcarce, D., \& Alvarez Marcos, J. (2004). Ciberperiodismo. Madrid: Editorial Sintesis.

Peña Fernández, S., Perez Dasilva, J., \& Genaut Arratibel, A. (2010). Tendencias en el diseño de los diarios vascos y navarros en Internet. Mediatika: cuadernos de medios de comunicación, 12, 105-137.

Peña- Fernández, S., Lazkano-Arrillaga, I., García-González, D., (2016). La transición digital de los diarios europeos: nuevos productos y nuevas audiencias. Comunicar. Revista científica de Eudocomunicación, 24, (46), 2736. doi: htto://dx.doi.org/10.3916/C46-2016-03

Pérez Marco, S. (2004). El concepto de hipertexto en el periodismo digital: análisis de la aplicación del hipertexto en la estructuración de las noticias de las ediciones digitales de tres periodicos españoles (www.elpais.es, www.elmundo.es, www.abc. es). Madrid: Servicio de publicacionesUniversidad Complutense de Madrid.

Pérez Martinez, V. M. (2009). Multimedialidad e interactividad en la cobertura informativa de las elecciones presidenciales de los Estados Unidos de 2008 en la cobermedios españoles. RLCS, Revista Latina de Comunicación Social, 64. doi: 10.4185/RLCS-64-2009-814-161-175

Salaverria, R. (2004). Diseñando el lenguaje para el ciberperiodismo. Chasqui, 86, 41-45.

Salaverria, R., \& Sancho, F. (2007). Del papel a la web: Evolución y claves del diseño periodístico en internet. En A. Larrondo Ureta, \& A. Serrano Tellería, Diseño periodístico en Internet, 207-239. Bilbao: Servicio de publicaciones de la Universidad del País Vasco.

Sánchez-Valle, M., \& Frutos Torres, B. (2008). Recursos creativos de la publicidad en Internet. Doxa Comunicación, 5, 159-188.

Varela, J. (2003). La prensa en Internet se paga. Chasqui, revista latinoamericana de comunicación, 82, 38-45. doi:http://dx.doi.org/10.16921/chasqui.v0i82.472

Wimmer, R., \& Domininck, J. (2001). Introducción a los medios masivos de comunicación. Mejico: Paraninfo. 